\title{
Innate immune modulation in EBV infection
}

Shunbin Ning

\begin{abstract}
Epstein-Barr Virus (EBV) belongs to the gammaherpesvirus family, members of which are oncogenic. Compared with other closely related herpesviruses, EBV has developed much more elaborate and sophisticated strategies for subverting host immune system, which may account for its high prevalence in immune competent hosts. Thus, study of EBV-specific immune dysregulation is important for understanding EBV latency and oncogenesis, and will identify potential molecular targets for immunotherapeutic interventions. Here I summarize the recent findings of individual EBV products in regulating host immune responses, with emphasis on the innate immune modulation.
\end{abstract}

\section{Introduction}

Epstein-Barr Virus (EBV), known as human herpesvirus 4 (HHV4), is the first identified human cancer virus that has been shown to be associated with the development of a wide spectrum of B-cell lymphoproliferative disorders including Burkitt's lymphoma (BL), Posttransplant lymphoproliferative disorder (PTLD), and Hodgkin and non-Hodgkin lymphomas, as well as epithelial cancers including Nasopharyngeal carcinoma (NPC) and some forms of gastric carcinoma [1]. EBV is also associated with lymphomas occurring in rare patients with congenital immunodeficiency such as X-linked lymphoproliferative syndrome (XLP) [2], and plays a role in lymphoproliferative disorders which most often occur in immunocompromised patients with human immunodeficiency virus (HIV) infection (e.g. central nervous system lymphoma) or after solid organ transplantation. EBV, together with Kaposi's sarcoma-associated herpesvirus (KSHV/HHV8) and human papillomavirus (HPV), are three oncogenic viruses causally involved in acquired immune deficiency syndrome (AIDS)-associated malignancies [3].

Herpesviruses are fascinating models for scientific research as they establish lifelong persistent infections in normal immunocompetent healthy hosts as well as are able to be reactivated (replicate) for spreading to new hosts. Human herpesviruses are of particularly medical importance because they are associated with severe diseases and cancers in immunocompromised hosts [4].

\footnotetext{
Correspondence: sning@med.miami.edu

Viral Oncology Program, Sylvester Comprehensive Cancer Center; Division of Hematology/Oncology, Department of Medicine, Miller School of Medicine, University of Miami, Miami, Florida 33136, USA
}

Among herpesviruses, EBV is a well-established paradigm for the study of herpes viral infection, persistence, and associated malignancies [4].

\section{EBV infection and life cycle}

EBV is spread by saliva contact, and then crosses mucosal epithelium in order to infect B cells in underlying secondary lymphoid tissues like the tonsils and adenoids. Besides spread by saliva contact, EBV may be sexually transmitted [5]. Breast milk of nursing mothers may also contain EBV which could be from an uncommon route of vertical transmission [6]. In healthy hosts, the immune system forces invading EBV to enter the destination "true latency" (latency 0 ) where the virus hides inside the nucleus of lymphocytes without manifesting any symptoms. The virus in "true latency" is neither pathogenic nor visible to the host immune system due to the lack of any viral protein production. But before the establishment of the final "true latency", the virus goes through several different "transitional" latency programs, named latency 3,2 and 1, which selectively express several of the nine viral latent proteins as well as noncoding RNAs (EBERs, BARF0, and miRNAs) and are associated with EBV oncogenesis [4]. Persistent latent infection is also characterized by stable numbers of infected B cells in the blood and by the steady shedding of infectious virus into saliva. The virus is continuously surveilled by the host immune system in persistent infection [7]. However, it is invisible to the host immune system since these long-lived B cells are quiescent and express fewer proteins, and do not express any viral protein before their occasional division, 
during which only EBNA1, which is not recognized by cytotoxic T lymphocytes (CTLs), is expressed [8].

Besides latently infects lymphocytes and productively infects epithelial cells, EBV also infects follicular dendritic cells, mononuclear cells, plasma cells and smooth muscle cells. Infection of monocytes is likely productive [9]. However, in healthy carriers, EBV seems to be exclusively harbored in B lymphocytes [6,7]. In vitro infection of B cells leads to cell activation and proliferation, as well as outgrowth of transformed lymphoblastoid cell lines (LCLs, Latency 3).

Reactivation from latency in response to a specified signal requires viral genomic DNA replication and the synthesis of specific viral proteins for packing the newly replicated DNA into infectious virions. Two immediateearly (IE) transcription factors, BZLF1 and BRLF1, are responsible for expression of these packing proteins. EBV expresses a full repertoire of over 80 lytic proteins during replication period. In healthy hosts, the replication program has to be transient, rapid, and relatively rare to minimize the chances to be shut down by the host immune system. On the other hand, the virus has developed strategies to elude the immune response for successful generation of viral progeny $[4,7]$.

The host immune system plays pivotal roles in both lytic and latent infections. It is currently deemed that a delicate modulation between host immune system, tightly controlled gene expression during distinct viral latency programs, and limited replication, enables EBV to persist in immunocompetent hosts without doing much harm $[7,10]$. Thus, study of the interaction between the host immune system and EBV is critical for understanding how EBV controls the balance between immune responses, undesired proliferation, and cell death, for its oncogenic benefits, and will provide a basis for potential immunotherapy for EBV-associated malignancies. Dysregulation of EBV-specific immune responses is also characteristic of EBV-associated autoimmune diseases such as rheumatoid arthritis (RA) and systemic lupus erythematosus (SLE). CTL response to EBV infection has been well documented since the discovery of EBV [11]. However, significant progresses in characterizing individual viral proteins involved in evasion of the $T$ cell-mediated adaptive immune response have only been made in the last decade [12-16]. For example, the functional homologue of human IL10, BCRF1, elicits CD8 ${ }^{+} \mathrm{T}$ cell responses, and can be processed and presented to CD ${ }^{+}$CTLs through a TAP-independent pathway [17]. On the other hand, how EBV regulates the host innate immune system is much less understood, and only limited studies on this important subject in EBV biology have been reported recently. Here I summarize these findings which have identified individual EBV products (including proteins, noncoding RNAs, and EBV genomic DNA) involved in regulating the host immune responses in both lytic and latent infections, with focus on their roles in innate immune modulation.

\section{Elicitation of innate immune responses}

In immunocompetent hosts, the attachment or entry of herpesviruses elicits a vigorous $\mathrm{CD}^{+} \mathrm{T}$ cell-mediated adaptive immune response against infected cells [10]. In the meantime, like other viruses, at the early stage of infection, herpes viral infection mounts innate immune responses in the host cell, significantly manifested by activation of signaling pathways mediated by Toll-like receptors (TLRs) [18-20].

\section{GP350}

Numerous studies with EBV GP350 (encoded by BLLF1), the major envelope glycoprotein which mediates EBV entry into B cells through interaction with its $B$-cell receptor CD21, have shown that acute and chronic EBV infections in vitro result in changes in secretion of TNF- $\alpha$, IL-1 $\beta$, IL-6, and IL-10 [21]. Like other herpesviruses such as herpes simplex virus (HSV) [22], varicella zoster virus (VZV) [19] and cytomegalovirus (CMV) [23], intact EBV virions can be recognized by TLR2 in epithelial cells and monocytes, and this process is likely mediated by GP350, suggesting that GP350 may act as a ligand for TLR2 [24] (Figure 1).

\section{EBV dUTPase}

In addition to the envelope protein GP350, the nonstructural protein dUTPase, which is encoded by the gene BLLF3 and is one of the early antigens (EA), is also a ligand recognized by TLR2 [25]. Recognition of EBV dUTPase by TLR2 activates NFkkappaB via a MyD88-dependent signaling cascade, and induces expression of proinflammatory cytokines in macrophages [25] (Figure 1). EBV LF1 (ORF10) and LF2 (ORF11) both contain a dUTPase-like domain. However, LF2 dysregulation of host immune response may be independent of its dUTPase-like domain [26].

\section{EBERS}

In latent infection, EBV constitutively encodes two noncoding and nonpolyadenylated small nuclear RNAs, EBV-encoded small nuclear RNA 1 (EBER1) and EBER2, which form dsRNA-like stem-loop structure by intermolecular base-pairing. EBERs have extensive structural similarity to adenoviruses VA1 and VA2 as well as cellular U6 small RNAs. EBERs are transcribed by RNA polymerase III and therefore characterized by a 5'triphosphate moiety [27]. These features (dsRNA-like structure and 5'-PPP) render EBERs capable to function as ligands for the intracellular RNA receptor, Retinoic acid-inducible gene I (RIG-I). Recognition of EBERs by 


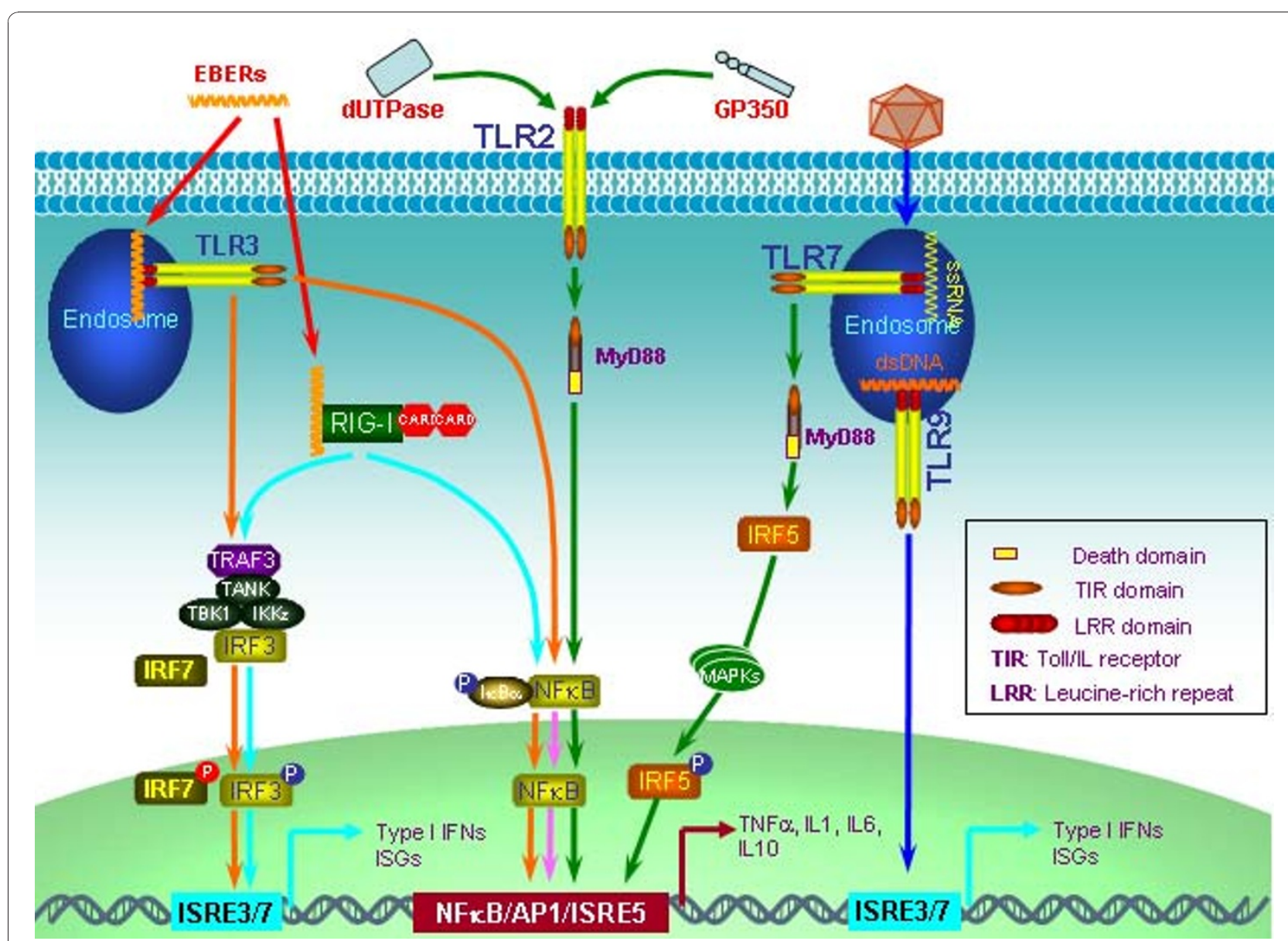

Figure 1 Elicitation of innate immune response in EBV infection. EBV dUTPase and GP350 act as ligands for TLR2. EBV EBERs can mount innate immune responses via both TLR3 and RIG-I signaling pathways. Infection of EBV also activates TLR9 signaling leading to IFNa production in pDCs. In latency, EBV manipulates the TLR7/IRF5 signaling pathway, which promotes cell proliferation. EBV products are indicated in red fonts.

RIG-I activates interferon regulatory factor 3 (IRF3) and induces interferons (IFNs), IFN-stimulated genes (ISGs) [28], and the anti-inflammatory cytokine IL10 [29] (Figure 1). EBERs especially EBER1 can also be released by secretion of the cellular partner, La (systemic lupus erythematosus-associated antigen), from EBV-infected cells and then lead to immune activation through recognition by TLR3 and induce type I IFNs and inflammatory cytokines [30] (Figure 1). In addition to RIG-I and TLR3, EBERs also bind to IFN-inducible dsRNA-dependent protein kinase (PKR), and inhibit PKR phosphorylation and mediated apoptosis [31] (Figure 1).

Type I IFNs and proinflammatory cytokines induced by EBER1 are released from EBV-infected cells [30]. Thus, EBER1 may play a role in immunopathologic diseases associated with acute EBV infection such as infectious mononucleosis (IM), chronic active EBV infection, and EBV-associated hemophagocytic lymphohistiocytosis, as well as in EBV-associated autoimmune diseases such as SLE.
In addition to EBERs, EBV latency expresses a CGrich transcript, IR4, with dsRNA-like structure. IR4 induces type I IFNs through unclear mechanism [32].

\section{EBV and TLR signaling}

Interaction between viruses and TLR signaling plays a pivotal role in virus-mediated innate immune elicitation and evasion. As stated above, EBV GP350, dUTPase, and EBERs can orchestrate TLR-mediated innate immune responses. Furthermore, increasing evidence has disclosed the interaction between EBV and TLR signaling with distinct outcomes, depending on cell types. In B lymphocytes, primary infection of EBV induces expression of TLR7 and downregulates expression of TLR9, as well as activates TLR7 signaling leading to expression of the downstream target IRF5 and cell proliferation [33] (Figure 1). Controversially, another study has reported that primary infection of EBV impairs the effect of TLR7/8/9 stimulation on B cell proliferation [34]. In plasmacytoid dendritic cells, infection of EBV 
activates TLR9 signaling pathway leading to IFN $\alpha$ production, and promotes activation of NK cells and IFN $\gamma$ producing CD3+ T cells [35] (Figure 1). Since TLR9 recognizes CpG DNA motifs from bacterial or viral genomes, presuming that EBV genomic DNA may service as TLR9 ligand. In monocytes, both TLR9 and TLR2 contribute to immune responses elicited by EBV infection $[24,36]$. As such, the murid gammaherpesvirus 68 (MHV68), which is an animal model for study of human gammaherpesviruses, also activates antiviral immune responses in dendritic cells through TLR9 signaling pathway [37]. However, primary infection of KSHV, another gammaherpesvirus, results in TLR3-dependent induction of proinflammatory chemokines and IFN, most notably CXCL10 and IFN $\beta$ in monocytes [38]. Interestingly, TLR7/8 stimulation also reactivates KSHV from latency [38].

\section{EBV and autoimmune diseases}

EBV has been implicated in autoimmune diseases including multiple sclerosis [39], RA [40] and SLE [41], underscored by the fact that EBNA1 was initially identified as the target antigen of sera from RA patients [42]. EBNA1 is expressed in all types of latency as well as lytic infection. Three fragments of EBNA1 protein, including 398-PPPGMRPP-404, 35-GPAGPRGGGRGRGRGRGRGHNDGG-58, and 58-GGSGSGPRHRDGVRR-72 mimics the self-antigens Sm B/B', Sm D1, and Ro, respectively, and therefore EBNA1 is believed to play a potential role in SLE [43]. Similarly, EBNA2 amino acids 354-GRGKGKSRDKQRKPGGPWRP-373 mimics Sm D1 antigen and may also contribute to SLE [43].

In addition to EBNA1 and EBNA2, EBERs exist in a snRNP complex containing La antigen specific to SLE and Sjogren syndrome, and therefore are recognized specifically by La antibody [44]. Given that recent studies showing the ability of EBER1 to provoke immune responses [28,30,31], it is very intriguing to study if EBER1 play a role in SLE in certain population.

Considering that TLRs, including TLR7, -8 , and -9, are also implicated in autoimmune diseases $[45,46]$, these TLRs may also contribute to EBV-associated autoimmune diseases, since EBV is able to regulate their expression [33,34] and may have some other interactions with signaling pathways mediated by these TLRs.

\section{Evasion of innate immune responses}

Most viruses have evolved to encode strategies to elude host immune responses for successful replication in the host cell [47-53]. The fact that EBV infects and establishes life-long persistence in more than $95 \%$ of the adult population indicates that it is very successful in subverting host immune surveillance. In fact, EBV encodes more ingenious tricks such as invoking the host ubiquitination-proteasome system, compared with its close member in the gamma herpes family, KSHV, which encodes a larger volume of products for this purpose. KSHV infects less than $2 \%$ of the general population, indicating striking differences in their prevalence and abilities to subvert host immune surveillance. Thus, EBV has been a paradigm for studying host-virus interactions. However, despite this fact and its medical importance, EBV has been poorly understood in terms of its evasion of host innate immunity. From limited findings reported in recent years, three main strategies can be identified for this purpose: (1) manipulating type I and II IFN Jak-STAT signaling pathways; (2) regulating expression and activity of IRFs; and (3) repressing apoptosis signaling pathways.

\section{Immune evasion in latency}

Limiting the number of expressed viral proteins and the levels of each expressed viral protein are likely two main strategies for EBV to escape the host immune system in latency [13]. EBV only expresses limited proteins in latency (9 in latency 3 and less in latency 1 and 2), and both EBNA1 and EBNA3C have been shown to be able to limit their own levels. In order to perform normal latency functions with these limited proteins, EBV encodes additional non-translated small RNAs (EBERs and miRNAs), which can not be detected by $\mathrm{T}$ cells looking for small peptides presented on MHC molecules [13]. In addition, memory B cells, the potential site for EBV long-term persistence [54], are not visible to immune system [8].

\section{EBNA1}

EBV EBNA1 is the only EBV protein expressed in all latency program and lytic cycle, and is essential for persistence of EBV genome and establishment of latency in the host cell. EBNA1 is a typical example that escapes proteasomal processing, a process for the generation of peptides for the MHC class I antigen presentation. The long Gly-Ala repeats of EBNA1 are necessary for its escape of proteasomal processing through possible interference with the recognition and unfolding functions of the $19 \mathrm{~S}$ subunit $[3,55]$ (Figure 2). The KSHV functional homolog of EBNA1, latency-associated nuclear antigen (LANA), also blocks proteasomal degradation and inhibits MHC class I-mediated antigen presentation [56]. Furthermore, EBNA1 prevents its own synthesis to keep at low but sustainable levels to avoid recognition by CTL [57]. Paradoxically, EBNA1 contains 3 peptide fragments which cross-react with three autoantigens and therefore may contribute to development of autoimmune disorders SLE, RA and multiple sclerosis [43].

EBNA1 recruits the host CK2 kinase to phosphorylate promyelocytic leukaemia nuclear protein (PML, also 


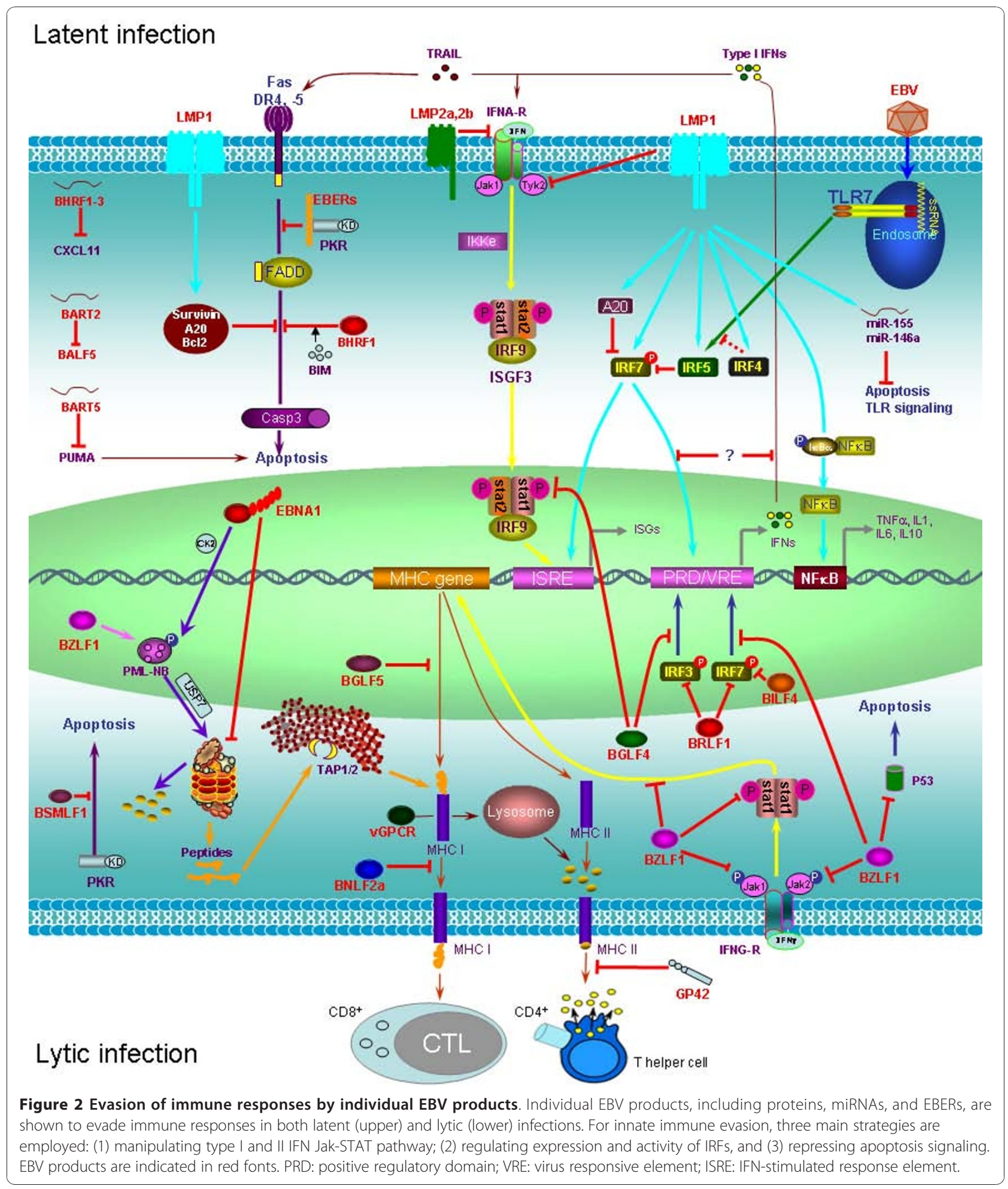

known as TRIM19 and RNF71) nuclear bodies (PML$\mathrm{NBs}$ ), and this phosphorylation leads to PML disruption through the ubiquitination pathway mediated by the ubiquitin-specific protease 7 (USP7, also known as herpesvirus-associated ubiquitin-specific protease (HAUSP)) in NPC cell lines $[58,59]$ (Figure 2). PML is an ISG which is a multiple functional protein with an important role in antiviral responses [60].

Recent studies have shown that EBNA1, in addition to EBNA3C and LMP1, promotes genomic instability and 
reactive oxygen species (ROS)-mediated DNA damage response [61,62], and may facilitate c-myc translocation. These findings argue that EBNA1 is a potential oncogene [63].

\section{LMP1}

Latent membrane protein 1 (LMP1) is accepted as the principal EBV oncoprotein which promotes cell growth and transformation in multiple cell backgrounds and in transgenic mice. As a member of the tumor necrosis factor receptor (TNFR) superfamily, LMP1 shares many signaling intermediates with TLRs, and both LMP1 and TLRs activate NF $\kappa$ kappaB, a subset of IRFs, and AP1. Furthermore, LMP1 is a pleiotropic factor with distinct functions including metastasis, apoptotic resistance, and immune modulation, which heavily depend on its proper intracellular trafficking and the host cellular context [64]. It has been shown that at least in human embryonic kidney (HEK) cells, LMP1 principally signals from intracellular compartments [65]. The immune modulation function of LMP1 may associate with exosome which plays a role in antigen transfer. In fact, LMP1 is enriched in exosomes isolated from EBV-positive B cells and epithelial cells, and may stimulate biogenesis and secretion of exosomes in these cells [64]. In EBV-transformed B lymphocytes, a small portion of LMP1 undergoes phosphorylation, and phosphorylated LMP1 is preferentially associated with vimentin in the cytoskeleton network [66].

LMP1 N-terminal transmembrane domain interacts with Tyk2 and consequently, suppresses phosphorylation of both STAT1 and -2 and subsequently blocks type I IFN-mediated antiviral responses [67]. Paradoxically, LMP1 has also been shown to stimulate tyrosine phosphorylation of STAT1 and induces its expression in EBV-transformed B cells $[68,69]$. LMP1 was also shown to have antiviral effect by inducing type I IFNs upon superinfection through activation of NF $\kappa$ kappaB and IRF7 by its $\mathrm{C}$-terminal activation regions (CTARs) [70] and by inducing some ISGs such as STAT1, 2',5'-oligoadenylate-synthetases (OAS) and ISG15 [71]. Furthermore, LMP1 induces a larger spectrum of genes involved in immune regulation such as chemokines CCL17 and CCL22, interleukins IL10, IL8 and IL6, and antigen processing and presentation proteins MHC class I and II and TAP2 (Figure 2). Moreover, LMP1 expressed at high levels induces autophagy [72], a cellular process which enhances antigen presentation to expose the infected cells to immune system. Thus, LMP1 seems to have opposite and diverse functions in immune modulation. In line with its immune repression function, an evolutionarily well-conserved immunosuppressive domain has been identified in its first transmembrane helix located at the LALLFWL sequence [64]. Regulation of type I JakSTAT IFN pathway by LMP1 may represent an evolved strategy for EBV to balance the complexity of EBV/host interaction for its long-term persistence.

Apoptosis plays an important role in viral innate immune responses [73]. LMP1 is a well known antiapoptotic protein which induces some anti-apoptotic proteins such as Survivin, A20, and Bcl-2 (Figure 2).

Besides its immune modulation role in latency, LMP1 is upregulated in hairy leukoplakia, the only pathologic manifestation of permissive EBV replication, possibly providing survival and immune evasion signals [74].

For a comprehensive understanding of the immune modulation functions of LMP1, see the excellent review [64].

\section{EBERs}

As stated above, EBERs can orchestrate immune responses mediated by TLR3 or RIG-I and induces inflammatory cytokines and type I IFNs. EBERs-induced type I IFNs can trigger apoptosis in EBV-infected cells [31], and helps the infected cells prevent from superinfection. But EBERs do not confer IFN resistance [75]. EBV has developed strategies to counteract this IFN-induced apoptosis. First, EBERs themselves binds to PKR in vitro, a key mediator of the antiviral effect of IFNs, and inhibit PKR- or IFN $\alpha$-mediated apoptosis [31] (Figure 2), although in BL cells, EBER inhibition of PKR-mediated apoptosis is likely not accomplished by direct inhibition of PKR [76]. Second, BHRF1, a homolog of cellular Bcl-2, blocks apoptosis by binding to a limited amount of Bim [77] (Figure 2). Third, as stated above, LMP1 induces expression of anti-apoptosis proteins. In addition, EBNA2 is resistant to IFN-induced anti-proliferation by reducing or abolishing expression of selected ISGs including ISG54, PKR, OAS, and IFI6-16 [78].

\section{EBV-encoded miRNAs}

EBV encodes at least 25 miRNAs [79]. These miRNAs are encoded by two transcripts, one set in intronic regions of the BamH I-A rightward transcript (BART) gene and the other set maps to the 5'-UTR (BHRF1-1 miRNA) and 3-UTR (BHRF1-2, 1-3 miRNAs) of the BHRF gene. The three BHRF1 miRNAs are expressed during type 3 latency while the large cluster of BART miRNAs (22 miRNAs) are expressed during type 2 latency [80]. With the exception of miR-BART2, all of the BART-derived miRNAs are mapped to two clusters. BART2 miRNA is highly expressed in primary BL (type 1 ) and primary effusion lymphomas (PEL). The functions of these miRNAs are largely unknown $[81,82]$, but recently their important roles in EBV pathogenesis and oncogenesis have been increasingly recognized. BART5 miRNA targets PUMA, a pro-apoptotic factor of the $\mathrm{Bcl} 2$ family, and therefore promotes host cell survival [83]. BART2 miRNA targets the EBV DNA polymerase BALF5 for degradation, and therefore effectively inhibits lytic replication [84]. BHRF1-3 miRNA represses expression of CXCL11 [81]. 


\section{EBV-induced host miRNAs}

miR-155 is produced from B cell intergration cluster (BIC) transcript, and is a novel crucial regulator of innate immunity, and it is also an important oncogenic miRNA (oncomiR) that is implicated in various lymphoid malignancies. miR-155 targets SHIP1 [85], IKKe [86], Table 2 [87], SOCS1 [88], and MyD88 [89], all of which are important intermediates of innate immune signaling pathways. SHIP1, IKKe, and SOCS1 also play roles in cancers. We have evidence showing that miR155 also targets SHIP1 in the EBV context (data to be published). In addition, miR-155 targets FOXO3a, and therefore plays an important role in breast cancers [90]. Unlike KSHV which encodes a viral ortholog of miR155 [91,92], EBV does not encode miR-155 ortholog but induces expression of cellular miR-155 by LMP1 signaling through NF $\kappa$ kappaB and AP1 [93-95]. We have evidence showing that BIC transcript is also induced by IRF4 in EBV latency as well as in human T-cell leukemia virus 1 (HTLV1)-infected cells, and the levels of BIC and IRF4 are correlated in HTLV1-associated adult $\mathrm{T}$ cell leukemia/lymphoma (ATLL) tumors (data to be published).

In addition, EBV induces miR-146, miR-21, miR-23a, miR-24, miR-27a, and miR-34a in its latency [96-98]. Like miR-155, both miR-146 and miR-21 are also oncogenic and are important regulators of innate immune responses. miR-146 targets TRAF6, IRAK1 and -2, and therefore attenuates type I IFN production in macrophages [99]. miR-21 targets the proinflammatory tumor suppressor PDCD4 and therefore promotes cell transformation and negatively regulates TLR4 signaling $[100,101]$.

\section{EBNA2}

EBNA2 has resistance to type I IFNs by reducing or abolishing expression of four ISGs: ISG54, PKR, OAS, and IFI6-16 [78]. However, EBNA2 can stimulate IFN $\beta$ expression and ISGF3 activity in BL cell lines [102].

\section{LMP2A and $2 B$}

LMP2A and -2B limit IFN signaling by promoting turnover of both type I and II IFN receptors, IFNAR and IFNGR [103].

\section{Evasion of IRF7-mediated IFN responses in latency}

EBV type 3 latency expresses a few more proteins than other latency programs, and mainly exists in immunocompromised hosts in vivo and lymphoblastoid cell lines in vitro. This latency is associated with distinct lymphoproliferative diseases in patients infected with HIV or suffering from other immunodeficiency conditions, such as iatrogenic immunodeficiency following solid organ transplantation. Latency 3 also exists in healthy people [104], presumably as the transition process to the destination "true latency".
LMP1 is expressed at a much higher level in latency 3 compared with other latency programs. We have shown ample evidence that LMP1 in latency 3 induces as well as activates IRF7 [105-107], the "master" regulator of type I IFN responses [108]. However, activated IRF7 does not induce considerable type I IFNs in EBV latency. The mechanism underlying this paradox is unclear. Understanding how EBV escapes the IRF7/IFN signaling pathway but retains IRF7's oncogenic activity is of great interest, as their outcomes shape not only the immune response to viral infection, but also affect aspects of host cell proliferation and survival. Recently, another IRF7 splicing variant, IRF7C, which is also induced by LMP1, has been identified to inhibit IRF7 transcriptional activity by competing with IRF7 for binding to IFN promoters [109]. This may provide a valuable clue for escape of IRF7-mediated IFN signaling in EBV latency. We are performing genome-wide screening to identify regulators of the IRF7/IFN signaling in EBV latency.

\section{Immune evasion in lytic cycle EBV GPCR}

A systematic screen of EBV lytic genes has identified BILF1, the EBV G protein-coupled receptor (GPCR) homolog which has constitutive signaling functions, as a specific inhibitor for MHC class I presentation on cell surface [110]. BILF1 targets MHC class I molecules for lysosomal degradation, and therefore abrogates its recognition by immune $\mathrm{T}$ cells (Figure 2). However, BILF1 exerts this effect through direct interaction with MHC class I complexes, independently of its GPCR signaling, and the underlying mechanism is distinct from those of other viral proteins which target MHC class I for degradation [110]. BILF1 also constitutively inhibits PKR phosphorylation [111,112]. KSHV GPCR homolog (ORF74) does not have this function, whereas the BILF1 homolog of the Rhesus $\gamma_{1}$-herpesvirus CeHV15 has similar function with EBV BILF1 in downregulation of MHC class I [110].

\section{BGLF5 and BNLF2a}

Two other EBV proteins have been described which significantly suppress adaptive immune responses. BGLF5, the EBV alkaline exonuclease (DNase), helps EBV to escape host $\mathrm{T}$-cell recognition and elimination of the infected cell by shutting off the expression of $\mathrm{MHC}$ class I and II genes [113]. BNLF2a, an EBV lytic cycle early protein, blocks MHC class I presentation through inactivation of the TAP1/TAP2 peptide transporter to impair $\mathrm{CD}^{+} \mathrm{T}$-cell response $[114,115]$ (Figure 2).

\section{BZLF1 and BRLF1}

The IE transcription factor BZLF1 is homologous to HSV1 ICP0 and host AP1. Like HSV1 ICP0 and EBV 
EBNA1, BZLF1 also disrupts PML [116]. BZLF1 specifically inhibits IFN $\gamma$ signaling at multiple levels: BZLF1 inhibits IFN $\gamma$-stimulated STAT1 Tyr701 phosphorylation as well as tyrosine phosphorylation of Jak1 and Jak2, decreases expression of IFN $\gamma \mathrm{R} \alpha$, and reduces IFN $\gamma$ induced MHC II expression [117]. BZLF1 interacts with P53 and inhibits transcription of both proteins. BZLF1 also targets P53 protein for degradation through MDM2-independent ubiquitination pathway [118] (Figure 2). In addition, as a transcription factor, BZLF1 inhibits TNFR1 expression through direct interaction with C/EBP proteins [119].

We have shown that BZLF1 inhibits IRF7 transcriptional activity [120]. BZLF1 and IRF7 physically interact. But BZLF1 had no effect on IRF7 nuclear translocation. The exact mechanism remains further study.

The other IE protein, BRLF1, decreases expression of IRF3 and -7, and therefore negatively regulates IFN responses to facilitate viral replication [121] (Figure 2).

BGLF4

BGLF4, the only EBV protein kinase (PK) whose ortholog UL13 in HSV1 has been implicated in counteracting IFN production [122], was identified as an IRF3-interacting protein in yeast two-hybrid screening [123]. BGLF4 phosphorylates IRF3 in vitro and does not prevent IRF3 dimerization and nuclear translocation. Phosphorylation of IRF3 by BGLF4 did not result in its proteasomal degradation, instead, diminished IRF3 binding to DNA, probably through affecting IRF3 optimal conformation for stable DNA binding [123] (Figure 2). BGLF4 also inhibits STAT1 Tyr701 phosphorylation [123] (Figure 2).

\section{BILF4}

Screening of EBV ORF library has identified BILF4 (LF2), which is also expressed at IE stage, as a potent inhibitor for IRF7-stimulated IFN promoter activity [26]. This inhibition effect is specific to IRF7 but not to IRF3. BILF4 is located in the nucleus and does not inhibit IRF7 phosphorylation and nuclear translocation; instead, it interrupts IRF7 dimerization through interaction with IRF7 central IRF association domain (IAD) [26]. Rhesus lymphocryptovirus LF ortholog has similar function with EBV LF2 [26]. LF2 is not necessary for EBV replication; in fact, it inhibits EBV replication [124].

\section{BARF1}

EBV-encoded BARF1 functions as a colony-stimulating factor 1 (CSF1) receptor for human CSF1, which is known to induce proliferation of bone marrow macrophages and promotes mononuclear cells to release cytokines such as type I IFNs, TNF $\alpha$, and IL1 [125].

\section{BSMLF1}

BSMLF1 is known as SM, BMLF1, EB2 and Mta. BSMLF1 is a transactivator and mRNA export factor that is essential for EBV replication. BSMLF1 binds to and inhibits PKR activation, and also interacts with TAP, CRM1, and PML-NB P110b subunit [126].

\section{GP42}

The envelope glycoprotein, GP42 which is encoded by BZLF2, binds to MHC class II and mediates viral entry to B cells. Binding of GP42 to MHC class II subverts $\mathrm{CD}^{+} \mathrm{T}$ cell activation through disruption of the interaction between MHC class II and T cell receptor (TCR) [14] (Figure 2).

\section{Perspectives}

It is clear that modulation of the host innate immune responses is a key component in EBV lifecycle. EBV, compared with other herpesviruses, encodes more sophisticated and successful strategies for this purpose. EBV encodes fewer products to accomplish this goal and successfully infects more than $90 \%$ of the population. This topic had not been taken into account until recently, emerging evidence show that EBV noncoding RNAs, IE transactivators, EBNA1, and LMP1, play important roles in these processes. However, these limited pieces of evidence are far away from clear to elucidate the whole picture of how EBV subverts host innate immune system. The study of EBV-noncoding RNAs and miRNAs in modulation of innate immune responses is just beginning, and will be the focus of this topic in the near future. How innate immune signaling pathways such as TLR and RLR signaling pathways respond to EBV primary infection is not clear, although this is the key to understand how the virus establishes latency after primary infection. Whether the innate immune signaling manipulates EBV reactivation is also an interesting question. Understanding the mechanisms whereby EBV evades innate immune responses to establish long-life latency and to develop malignancies is paramount for therapeutics of EBV-associated malignancies.

\section{Acknowledgements}

This work is supported by the State of Florida Biomedical Research Programs (1BN-07) and NCl (1P30CA147890-01).

\section{Competing interests}

The author declares that he has no competing interests.

Received: 10 October 2010 Accepted: 5 January 2011

Published: 5 January 2011

\section{References}

1. Maeda E, Akahane M, Kiryu S, Kato N, Yoshikawa T, Hayashi N, Aoki S, Minami M, Uozaki H, Fukayama M, Ohtomo K: Spectrum of Epstein-Barr virus-related diseases: a pictorial review. Jpn J Radiol 2009, 27:4-19.

2. Carbone A, Cesarman E, Spina M, Gloghini A, Schulz TF: HIV-associated lymphomas and gamma-herpesviruses. Blood 2009, 113:1213-1224.

3. Shackelford J, Pagano JS: Role of the ubiquitin system and tumor viruses in AIDS-related cancer. BMC Biochem 2007, 8:S8. 
4. Thorley-Lawson DA, Duca KA, Shapiro M: Epstein-Barr virus: a paradigm for persistent infection - for real and in virtual reality. Trends Immunol 2008, 29:195-201.

5. Pagano JS: Is Epstein-Barr Virus transmitted sexually? The Journal of Infectious Diseases 2007, 195:469-470.

6. Gulley ML, Tang W: Laboratory assays for Epstein-Barr Virus-related disease. J Mol Diagn 2008, 10:279-292.

7. Thorley-Lawson DA: Epstein-Barr virus: exploiting the immune system. Nat Rev Immunol 2001, 1:75-82.

8. Hochberg D, Middeldorp JM, Catalina M, Sullivan JL, Luzuriaga K, ThorleyLawson DA: Demonstration of the Burkitt's lymphoma Epstein-Barr virus phenotype in dividing latently infected memory cells in vivo. Proc Natl Acad Sci USA 2004, 101:239-244

9. Savard M, Belanger C, Tardif M, Gourde P, Flamand L, Gosselin J: Infection of primary human monocytes by Epstein-Barr Virus. J Virol 2000, 74:2612-2619.

10. Hislop AD, Taylor GS, Sauce D, Rickinson AB: Cellular responses to viral infection in humans: lessons from Epstein-Barr Virus. Annu Rev Immunol 2007, 25:587-617.

11. Rickinson $A B$, Kieff E: Epstein-Barr virus. In Fieds Virology.. 5 edition. Edited by: Knipe DM, Howley PM. Philadelphia, USA: Lippincott Williams 2007:2655-2700

12. Blake $\mathrm{N}$ : Immune evasion by gammaherpesvirus genome maintenance proteins. J Gen Virol 2010, 91:829-846

13. Munz C, Moormann A: Immune escape by Epstein-Barr virus associated malignancies. Semin Cancer Biol 2008, 18:381-387.

14. Ressing ME, Horst D, Griffin BD, Tellam J, Zuo J, Khanna R, Rowe M, Wiertz EJHJ: Epstein-Barr virus evasion of CD8+ and CD4+ T cell immunity via concerted actions of multiple gene products. Semin Cancer Biol 2008, 18:397-408.

15. Lautscham G, Rickinson A, Blake N: TAP-independent antigen presentation on MHC class I molecules: lessons from Epstein-Barr virus. Microbes Infect 2003, 5:291-299.

16. Hislop AD, Sabbah S: CD8+ T cell immunity to Epstein-Barr virus and Kaposi's sarcoma-associated herpes virus. Semin Cancer Biol 2008, 18:416-422.

17. Saulquin X, Bodinier M, Peyrat MA, Hislop A, Scotet E, Lang Fo, Bonneville $M$, Houssaint $E$ : Frequent recognition of BCRF1, a late lytic cycle protein of Epstein-Barr virus, in the HLA-B*2705 context: evidence for a TAP-independent processing. Eur J Immunol 2001, 31:708-715.

18. Zucchini N, Bessou G, Traub S, Robbins SH, Uematsu S, Akira S, Alexopoulou L, Dalod M: Cutting edge: overlapping functions of TLR7 and TLR9 for innate defense against a herpesvirus infection. J Immunol 2008, 180:5799-5803

19. Finberg RW, Knipe DM, Kurt-Jones EA: Herpes Simplex Virus and Toll-Like Receptors. Viral Immunol 2005, 18:457-465.

20. West J, Damania B: Upregulation of the TLR3 pathway by Kaposi's sarcoma-associated herpesvirus during primary infection. J Virol 2008, 82:5440-5449.

21. Mogensen TH, Paludan SR: Molecular pathways in virus-induced cytokine production. Microbiol Mol Biol Rev 2001, 65:131-150.

22. Kurt-Jones EA, Chan M, Zhou S, Wang J, Reed G, Bronson R, Arnold MM, Knipe DM, Finberg RW: Herpes simplex virus 1 interaction with Toll-like receptor 2 contributes to lethal encephalitis. Proc Natl Acad Sci USA 2004, 101:1315-1320.

23. Compton T, Kurt-Jones EA, Boehme KW, Belko J, Latz E, Golenbock DT, Finberg RW: Human Cytomegalovirus Activates Inflammatory Cytokine Responses via CD14 and Toll-Like Receptor 2. J Virol 2003, 77:4588-4596.

24. Gaudreault E, Fiola S, Olivier M, Gosselin J: Epstein-Barr virus induces MCP1 secretion by human monocytes via TLR2. J Virol 2007, 81:8016-8024.

25. Ariza ME, Glaser R, Kaumaya PT, Jones C, Williams MV: The EBV-encoded dUTPase activates NF-kB through the TLR2 and MyD88-dependent signaling pathway. J Immunol 2009, 182:851-859.

26. Wu L, Fossum E, Joo CH, Lee K, Shin YC, Johannsen E, Hutt-Fletcher LM, Hass J, Jung JU: Epstein-Barr virus LF2: An antagonist to type I interferon. J Virol 2009, 83:1140-1146.

27. Ablasser A, Bauernfeind F, Hartmann G, Latz E, Fitzgerald KA, Hornung V: RIG-I-dependent sensing of poly(dA:dT) through the induction of an RNA polymerase III-transcribed RNA intermediate. Nat Immunol 2009, 10:1065-1072.
28. Samanta M, Iwakiri D, Kanda T, Imaizumi T, Takada K: EB virus-encoded RNAs are recognized by RIG-I and activate signaling to induce type I IFN. EMBO J 2006, 25:4207-4214.

29. Samanta M, Iwakiri D, Takada K: Epstein-Barr virus-encoded small RNA induces IL-10 through RIG-I-mediated IRF3 signaling. Oncogene 2008, 27:4150-4160.

30. Iwakiri D, Zhou L, Samanta M, Matsumoto M, Ebihara T, Seya T, Imai S, Fujieda M, Kawa K, Takada K: Epstein-Barr virus (EBV)-encoded small RNA is released from EBV-infected cells and activates signaling from toll-like receptor 3. J Exp Med 2009, 10:2091-2099.

31. Nanbo A, Inoue K, Adachi-Takasawa K, Takada K: Epstein-Barr virus RNA confers resistance to interferon- $\alpha$-induced apoptosis in Burkitt's lymphoma. EMBO J 2002, 21:954-965.

32. Gao Y, Xue Sa, Griffin BE: Sensitivity of an Epstein-Barr Virus-positive tumor line, Daudi, to alpha interferon correlates with expression of a GC-rich viral transcript. Mol Cell Biol 1999, 19:7305-7313.

33. Martin HJ, Lee JM, Walls D, Hayward SD: Manipulation of the TLR7 signaling pathway by Epstein-Barr virus. J Virol 2007, 81:9748-9758.

34. Younesi V, Nikzamir H, Yousefi M, Khoshnoodi J, Arjmand M, Rabbani H, Shokri F: Epstein Barr virus inhibits the stimulatory effect of TLR7/8 and TLR9 agonists but not CD40 ligand in human B lymphocytes. Microbiol Immunol 2010, 54:534-541.

35. Lim WH, Kireta S, Russ GR, Coates PTH: Human plasmacytoid dendritic cells regulate immune responses to Epstein-Barr virus (EBV) infection and delay EBV-related mortality in humanized NOD-SCID mice. Blood 2007, 109:1043-1050

36. Fiola S, Gosselin D, Takada K, Gosselin J: TLR9 contributes to the recognition of EBV by primary monocytes and plasmacytoid dendritic cells. J Immunol 2010, 185:3620-3631.

37. Guggemoos S, Hangel D, Hamm S, Heit A, Bauer S, Adler H: TLR9 contributes to antiviral immunity during gammaherpesvirus infection. $J$ Immunol 2008, 180:438-443.

38. Gregory SM, Damania B: KSHV and the toll of innate immune activation. Cell Cycle 2009, 8:3246-3247.

39. Salvetti M, Giovannoni G, Aloisi F: Epstein-Barr virus and multiple sclerosis. Curr Opin Neurol 2009, 22:201-206.

40. Pohl D: Epstein-Barr virus and multiple sclerosis. Journal of the Neurological Sciences 2009, 286:62-64.

41. Munz C, Lunemann JD, Getts MT, Miller SD: Antiviral immune responses: triggers of or triggered by autoimmunity? Nat Rev Immunol 2009, 9:246-258.

42. Alspaugh MA, Shoji H, Nonoyama M: A search for rheumatoid arthritisassociated nuclear antigen and Epstein-Barr virus specific antigens or genomes in tissues and cells from patients with rheumatoid arthritis. Arthritis Rheum 1983, 26:712-720.

43. Poole BD, Scofield RH, Harley JB, James JA: Epstein-Barr virus and molecular mimicry in systemic lupus erythematosus. Autoimmunity 2006 39:63-70.

44. Lerner MR, Andrews NC, Miller G, Steitz JA: Two small RNAs encoded by Epstein-Barr virus and complexed with protein are precipitated by antibodies from patients with systemic lupus erythematosus. Proc Natl Acad Sci USA 1981, 78:805-809.

45. Baccala R, Hoebe K, Kono DH, Beutler B, Theofilopoulos AN: TLR-dependent and TLR-independent pathways of type I interferon induction in systemic autoimmunity. Nat Med 2007, 13:543-551.

46. Kim WU, Sreih A, Bucala R: Toll-like receptors in systemic lupus erythematosus; prospects for therapeutic intervention. Autoimmun Rev 2009, 8:204-208

47. Tsuchida T, Kawai T, Akira S: Inhibition of IRF3-dependent antiviral responses by cellular and viral proteins. Cell Res 2009, 19:3-4.

48. Bowie AG, Unterholzner L: Viral evasion and subversion of patternrecognition receptor signalling. Nat Rev Immunol 2008, 8:911-922.

49. Randall RE, Goodbourn S: Interferons and viruses: an interplay between induction, signalling, antiviral responses and virus countermeasures. J Gen Virol 2008, 89:1-47.

50. Unterholzner L, Bowie AG: The interplay between viruses and innate immune signaling: Recent insights and therapeutic opportunities. Biochem Pharmacol 2008, 75:589-602.

51. Roy CR, Mocarski ES: Pathogen subversion of cell-intrinsic innate immunity. Nat Immunol 2007, 8:1179-1187.

52. Weber F, Haller O: Viral suppression of the interferon system. Biochimie 2007, 89:836-842. 
53. Haller O, Kochs G, Weber F: The interferon response circuit: Induction and suppression by pathogenic viruses. Virology 2006, 344:119-130.

54. Babcock GJ, Decker LL, Volk M, Thorley-Lawson DA: EBV persistence in memory B cells in vivo. Immunity 1998, 9:395-404

55. Hansen $\mathrm{TH}$, Bouvier M: MHC class I antigen presentation: learning from viral evasion strategies. Nat Rev Immunol 2009, 9:503-513.

56. Zaldumbide A, Ossevoort M, Wiertz EJHJ, Hoeben RC: In cis inhibition of antigen processing by the latency-associated nuclear antigen I of Kaposi sarcoma Herpes virus. Mol Immunol 2007, 44:1352-1360.

57. Yin Y, Manoury B, Fahraeus R: Self-inhibition of synthesis and antigen presentation by Epstein-Barr Virus-encoded EBNA1. Science 2003, 301:1371-1374

58. Sivachandran N, Sarkari F, Frappier L: Epstein-Barr Nuclear Antigen 1 contributes to nasopharyngeal carcinoma through disruption of PML nuclear bodies. PLOS Pathog 2008, 4:e1000170

59. Sivachandran N, Cao JY, Frappier L: Epstein-Barr Nuclear Antigen 1 hijacks the host kinase CK2 to disrupt PML nuclear bodies. J Virol 2010, 84:11113-11123.

60. Everett RD, Chelbi-Alix MK: PML and PML nuclear bodies: implications in antiviral defence. Biochimie 2007, 89:819-830.

61. Gruhne B, Kamranvar SA, Masucci MG: EBV and genomic instability - a new look at the role of the virus in the pathogenesis of Burkitt's lymphoma. Semin Cancer Biol 2009, 19:394-400.

62. Gruhne B, Sompallae R, Masucci MG: Three Epstein-Barr virus latency proteins independently promote genomic instability by inducing DNA damage, inhibiting DNA repair and inactivating cell cycle checkpoints. Oncogene 2009, 28:3997-4008.

63. Schulz TF, Cordes S: Is the Epstein-Barr virus EBNA-1 protein an oncogene? Proc Natl Acad Sci USA 2009, 106:2901-2902.

64. Middeldorp JM, Pegtel DM: Multiple roles of LMP1 in Epstein-Barr virus induced immune escape. Semin Cancer Biol 2008, 18:388-396.

65. Lam N, Sugden B: LMP1, a viral relative of the TNF receptor family, signals principally from intracellular compartments. EMBO J 2003, 22:3027-3038.

66. Liebowitz D, Kopan R, Fuchs E, Sample J, Kieff E: An Epstein-Barr virus transforming protein associates with vimentin in lymphocytes. Mol Cell Biol 1987, 7:2299-2308

67. Geiger TR, Martin JM: The Epstein-Barr Virus-encoded LMP-1 oncoprotein negatively affects Tyk2 phosphorylation and interferon signaling in human B cells. J Virol 2006, 80:11638-11650.

68. Richardson C, Fielding C, Rowe M, Brennan P: Epstein-Barr virus regulates STAT1 through latent membrane protein 1. J Virol 2003, 77:4439-4443.

69. Naijar I, Baran-Marszak F, Le Clorennec C, Laguillier C, Schischmanoff O, Youlyouz-Marfak I, Schlee M, Bornkamm GW, Raphael M, Feuillard J, Fagard R: Latent Membrane Protein 1 regulates STAT1 through NF-kBdependent interferon secretion in Epstein-Barr Virus-immortalized B cells. J Virol 2005, 79:4936-4943.

70. Xu D, Brumm K, Zhang L: The Latent Membrane Protein 1 of Epstein-Barr Virus (EBV) primes EBV latency cells for type I interferon production. J Biol Chem 2006, 281:9163-9169.

71. Zhang J, Das SC, Kotalik C, Pattnaik AK, Zhang L: The latent membrane protein 1 of Epstein-Barr virus establishes an antiviral state via induction of interferon-stimulated genes. J Biol Chem 2004, 279:46335-46342.

72. Lee DY, Sugden B: The latent membrane protein 1 oncogene modifies Bcell physiology by regulating autophagy. Oncogene 2008, 27:2833-2842.

73. Everett H, McFadden G: Viruses and apoptosis: meddling with mitochondria. Virology 2001, 288:1-7.

74. Webster-Cyriaque J, Middeldorp J, Raab-Traub N: Hairy Leukoplakia: an Unusual Combination of Transforming and Permissive Epstein-Barr Virus Infections. J Virol 2000, 74:7610-7618.

75. Swaminathan S, Huneycutt BS, Reiss CS, Kieff E: Epstein-Barr virus-encoded small RNAs (EBERs) do not modulate interferon effects in infected lymphocytes. J Virol 1992, 66:5133-5136.

76. Ruf IK, Lackey KA, Warudkar S, Sample JT: Protection from interferoninduced apoptosis by Epstein-Barr Virus small RNAs is not mediated by inhibition of PKR. J Virol 2005, 79:14562-14569.

77. Desbien AL, Kappler JW, Marrack P: The Epstein-Barr virus BCl-2 homolog BHRF1, blocks apoptosis by binding to a limited amount of Bim. Proc Natl Acad Sci USA 2009, 106:5663-5668.

78. Kanda K, Decker T, Aman P, Wahlstrom M, von Gabain A, Kallin B: The EBNA2-related resistance towards alpha interferon (IFN-alpha) in Burkitt's lymphoma cells affects induction of IFN-induced genes but not the activation of transcription factor ISGF-3. Mol Cell Biol 1992, 12:4930-4936

79. Skalsky RL, Cullen BR: Viruses, microRNAs, and host interactions. Annual Review of Microbiology 2010, 64:123-141

80. Cosmopoulos K, Pegtel M, Hawkins J, Moffett H, Novina C, Middeldorp J, Thorley-Lawson DA: Comprehensive profiling of EBV microRNAs in nasopharyngeal carcinoma. J Virol 2009, 83:2357-2367.

81. Xia T, O'Hara A, Araujo I, Barreto J, Carvalho E, Sapucaia JB, Ramos JC, Luz E, Pedroso C, Manrique M, Toomey NL, Brites C, Dittmer DP, Harrington WJ Jr: EBV microRNAs in primary lymphomas and targeting of CXCL-11 by EBV-mir-BHRF1-3. Cancer Res 2008, 68:1436-1442.

82. Pfeffer S, Zavolan M, Grasser FA, Chien M, Russo JJ, Ju J, John B, Enright AJ, Marks D, Sander C, Tuschl T: Identification of virus-encoded microRNAs. Science 2004, 304:734-736.

83. Choy EY-W, Siu KL, Kok KH, Lung RW-M, Tsang CM, To KF, Kwong DL-W, Tsao SW, Jin DY: An Epstein-Barr virus-encoded microRNA targets PUMA to promote host cell survival. The Journal of Experimental Medicine 2008, 205:2551-2560.

84. Barth S, Pfuhl T, Mamiani A, Ehses C, Roemer K, Kremmer E, Jaker C, Hock J, Meister G, Grasser FA: Epstein-Barr virus-encoded microRNA miR-BART2 down-regulates the viral DNA polymerase BALF5. Nucleic Acids Res 2008, 36:666-675.

85. O'Connell RM, Chaudhuri AA, Rao DS, Baltimore D: Inositol phosphatase SHIP1 is a primary target of miR-155. Proc Natl Acad Sci USA 2009, 106:7113-7118.

86. Lu F, Weidmer A, Liu CG, Volinia S, Croce CM, Lieberman PM: Epstein-Barr Virus-induced miR-155 attenuates NF-KB signaling and stabilizes latent virus persistence. J Virol 2008, 82:10436-10443.

87. Rodriguez A, Vigorito E, Clare S, Warren MV, Couttet P, Soond DR, van Dongen S, Grocock RJ, Das PP, Miska EA, Vetrie D, Okkenhaug K, Enright AJ, Dougan G, Turner M, Bradley A: Requirement of bic/microRNA-155 for normal immune function. Science 2007, 316:608-611.

88. Jiang S, Zhang HW, Lu MH, He XH, Li Y, Gu H, Liu MF, Wang ED: MicroRNA-155 functions as an oncomiR in breast cancer by targeting the Suppressor of Cytokine Signaling 1 gene. Cancer Res 2010, 70:3119-3127.

89. Tang B, Xiao B, Liu Z, Li N, Zhu ED, Li BS, Xie QH, Zhuang Y, Zou QM, Mao XH: Identification of MyD88 as a novel target of miR-155, involved in negative regulation of Helicobacter pylori-induced inflammation. FEBS Letters 2010, 584:1481-1486.

90. Kong W, He L, Coppola M, Guo J, Esposito NN, Coppola D, Cheng JQ: MicroRNA-155 regulates cell survival, growth and chemosensitivity by targeting FOXO3a in breast cancer. J Biol Chem 2010, 285:17869-17879.

91. Gottwein E, Mukherjee N, Sachse C, Frenzel C, Majoros WH, Chi JT, Braich R Manoharan M, Soutschek J, Ohler U, Cullen BR: A viral microRNA functions as an orthologue of cellular miR-155. Nature 2007, 450:1096-1099.

92. Skalsky RL, Samols MA, Plaisance KB, Boss IW, Riva A, Lopez MC, Baker HV, Renne R: Kaposi's Sarcoma-Associated Herpesvirus encodes an ortholog of miR-155. J Virol 2007, 81:12836-12845.

93. Gatto G, Rossi A, Rossi D, Kroening S, Bonatti S, Mallardo M: Epstein-Barr virus latent membrane protein 1 transactivates miR-155 transcription through the NF-KB pathway. Nucleic Acids Res 2008, 36:6608-6619.

94. Yin Q, McBride J, Fewell C, Lacey M, Wang X, Lin Z, Cameron J, Flemington EK: MicroRNA-155 is an Epstein-Barr Virus-induced gene that modulates Epstein-Barr Virus-regulated gene expression pathways. J Virol 2008, 82:5295-5306.

95. Yin $\mathrm{Q}$, Wang $X, M c B$ ride J, Fewell C, Flemington E: B-cell receptor activation induces $\mathrm{BIC} / \mathrm{miR}-155$ expression through a conserved AP-1 element. J Biol Chem 2008, 283:2654-2662

96. Cameron JE, Fewell C, Yin Q, McBride J, Wang X, Lin Z, Flemington EK: Epstein-Barr virus growth/latency III program alters cellular microRNA expression. Virology 2008, 382:257-266.

97. Cameron JE, Yin Q, Fewell C, Lacey M, McBride J, Wang X, Lin Z, Schaefer BC, Flemington EK: Epstein-Barr Virus Latent Membrane Protein 1 induces cellular microRNA miR-146a, a modulator of lymphocyte signaling pathways. J Virol 2008, 82:1946-1958.

98. Motsch N, Pfuhl T, Mrazek J, Barth S, Grasser FA: Epstein-Barr virusencoded latent membrane protein 1 (LMP1) induces the expression of the cellular microRNA miR-146a. RNA Biol 2007, 4:131-137. 
99. Hou J, Wang P, Lin L, Liu X, Ma F, An H, Wang Z, Cao X: MicroRNA-146a feedback inhibits RIG-I-dependent type I IFN production in macrophages by targeting TRAF6, IRAK1, and IRAK2. J Immunol 2009, 183:2150-2158.

100. Sheedy FJ, Palsson-McDermott E, Hennessy EJ, Martin C, O'Leary JJ, Ruan Q, Johnson DS, Chen Y, O'Neill LAJ: Negative regulation of TLR4 via targeting of the proinflammatory tumor suppressor PDCD4 by the microRNA miR-21. Nat Immunol 2010, 11:141-147.

101. Lu Z, Liu M, Stribinskis V, Klinge CM, Ramos KS, Colburn NH, Li Y: MicroRNA-21 promotes cell transformation by targeting the programmed cell death 4 gene. Oncogene 2008, 27:4373-4379.

102. Kanda K, Kempkes B, Bornkamm GW, Gabain Av, Decker T: The Epstein-Barr Virus Nuclear Antigen 2 (EBNA2), a protein required for B lymphocyte immortalization, induces the synthesis of Type I interferon in Burkitts lymphoma cell lines. Biological Chemistry 2005, 380:213-221.

103. Shah KM, Stewart SE, Wei W, Woodman CBJ, O'Neil JD, Dawson CW, Young LS: The EBV-encoded latent membrane proteins, LMP2A and LMP2B, limit the actions of interferon by targeting interferon receptors for degradation. Oncogene 2009, 28:3903-3914.

104. Joseph AM, Babcock GJ, Thorley-Lawson DA: Cells expressing the EpsteinBarr Virus growth program are present in and restricted to the naive Bcell subset of healthy tonsils. J Virol 2000, 74:9964-9971.

105. Zhang L, Pagano JS: Interferon regulatory factor 7 is induced by EpsteinBarr virus latent membrane protein 1. J Virol 2000, 74:1061-1068.

106. Huye LE, Ning S, Kelliher M, Pagano JS: IRF7 is activated by a viral oncoprotein through RIP-dependent ubiquitination. Mol Cell Biol 2007 27:2910-2918.

107. Ning S, Campos AD, Darnay B, Bentz G, Pagano JS: TRAF6 and the three Cterminal lysine sites on IRF7 are required for its ubiquitination-mediated activation by the Tumor Necrosis Factor Receptor family member Latent Membrane Protein 1. Mol Cell Biol 2008, 28:6536-6546.

108. Honda K, Taniguchi T: IRFs: master regulators of signalling by Toll-like receptors and cytosolic pattern-recognition receptors. Nat Rev Immunol 2006, 6:644-658.

109. Zhao $Y, X u D$, Jiang $Y$, Zhang $L$ : Dual functions of interferon regulatory factors 7C in Epstein-Barr Virus-mediated transformation of human B lymphocytes. PLOS ONE 2010, 5:e9459.

110. Zuo J, Currin A, Griffin BD, Shannon-Lowe C, Thomas WA, Ressing ME, Wiertz EJ, Rowe M: The Epstein-Barr virus G-protein-coupled receptor contributes to immune evasion by targeting MHC class I molecules for degradation. PLoS Pathog 2009, 5:e1000255

111. Beisser PS, Verzijl D, Gruijthuijsen YK, Beuken E, Smit MJ, Leurs R, Bruggeman CA, Vink C: The Epstein-Barr Virus BILF1 gene encodes a G Protein-Coupled Receptor that inhibits phosphorylation of RNAdependent protein kinase. J Virol 2005, 79:441-449.

112. Paulsen SJ, Rosenkilde MM, Eugen-Olsen J, Kledal TN: Epstein-Barr VirusEncoded BILF1 is a constitutively active G Protein-Coupled Receptor. J Virol 2005, 79:536-546.

113. Rowe M, Glaunsinger B, van Leeuwen D, Zuo J, Sweetman D, Ganem D Middeldorp J, Wiertz EJHJ, Ressing ME: Host shutoff during productive Epstein-Barr virus infection is mediated by BGLF5 and may contribute to immune evasion. Proc Natl Acad Sci USA 2007, 104:3366-3371.

114. Croft NP, Shannon-Lowe C, Bell Al, Horst D, Kremmer E, Ressing ME, Wiertz EJ, Middeldorp JM, Rowe M, Rickinson AB, Hislop AD: Stage-specific inhibition of MHC class I presentation by the Epstein-Barr virus BNLF2a protein during virus lytic cycle. PLoS Pathog 2009, 5:e1000490.

115. Horst D, van Leeuwen D, Croft NP, Garstka MA, Hislop AD, Kremmer E, Rickinson AB, Wiertz EJHJ, Ressing ME: Specific targeting of the EBV lytic phase protein BNLF2a to the transporter associated with antigen processing results in impairment of HLA class I-restricted antigen presentation. J Immunol 2009, 182:2313-2324.

116. Saffert RT, Kalejta RF: Promyelocytic leukemia-nuclear body proteins: herpesvirus enemies, accomplices, or both? Future Virol 2008, 3:265-277

117. Morrison TE, Mauser A, Wong A, Ting JPY, Kenney SC: Inhibition of IFNY signaling by an Epstein-Barr Virus immediate-early protein. Immunity 2001, 15:787-799.

118. Zhang Q, Gutsch D, Kenney S: Functional and physical interaction between p53 and BZLF1: implications for Epstein-Barr virus latency. Mol Cell Biol 1994, 14:1929-1938.
119. Bristol JA, Robinson AR, Barlow EA, Kenney SC: The EBV BZLF1 protein inhibits TNFR1 expression through effects on cellular C/EBP proteins. J Virol 2010, 84:12362-12374.

120. Hahn AM, Huye LE, Ning S, Webster-Cyriaque J, Pagano JS: Interferon regulatory factor 7 is negatively regulated by the Epstein-Barr virus immediate-early gene, BZLF1. J Virol 2005, 79:10040-10052.

121. Bentz G, Liu R, Hahn A, Shackelford J, Pagano JS: Epstein-Barr virus immediate-early protein RTA negatively regulates interferon regulatory factors. Virology 2010, 402:121-128.

122. Gershburg E, Pagano JS: Conserved herpesvirus protein kinases. Biochimica et Biophysica Acta (BBA) - Proteins \& Proteomics 2008 1784:203-212.

123. Wang JT, Doong SL, Teng SC, Lee CP, Tsai CH, Chen MR: Epstein-Barr Virus BGLF4 kinase suppresses the Interferon Regulatory Factor 3 signaling pathway. J Virol 2009, 83:1856-1869.

124. Calderwood MA, Holthaus AM, Johannsen E: The Epstein-Barr virus LF2 protein inhibits viral replication. J Virol 2008, 82:8509-8519.

125. Cohen II, Lekstrom K: Epstein-Barr virus BARF1 protein is dispensable for B-cell transformation and inhibits alpha interferon secretion from mononuclear cells. J Virol 1999, 73:7627-7632.

126. Kieff E, Rickinson AB: Epstein-Barr virus and its replication. In Fields Virology. 5 edition. Edited by: Knipe DM, Howley PM. Philadelphia, USA: Lippincott Williams 2007:2603-2654.

doi:10.1186/2042-4280-2-1

Cite this article as: Ning: Innate immune modulation in EBV infection. Herpesviridae 2011 2:1.

\section{Submit your next manuscript to BioMed Central and take full advantage of:}

- Convenient online submission

- Thorough peer review

- No space constraints or color figure charges

- Immediate publication on acceptance

- Inclusion in PubMed, CAS, Scopus and Google Scholar

- Research which is freely available for redistribution

Submit your manuscript at www.biomedcentral.com/submit
C) Biomed Central 